\title{
DESENVOLVIMENTO URBANO DE LUÍS EDUARDO MAGALHÃES/BA: ECONOMIA E SEGREGAÇÃO
}

Jaquelyne Soares Balsani, Fabrícia Dias da Cunha de Moraes Fernandes Borges

Universidade do Oeste Paulista - UNOESTE, curso de Arquitetura e Urbanismo, Presidente Prudente, SP. E-mail: jaquelynebalsani@hotmail.com

\section{RESUMO}

Luís Eduardo Magalhães é uma cidade da mesorregião Extremo Oeste Baiano, do estado da Bahia. Com menos de duas décadas de emancipação e muitos problemas relacionados à sua configuração urbana, não se há estudos publicados que a abordem sob a análise do arquiteto e urbanista. Objetiva-se introduzir o conhecimento científico sobre o espaço intraurbano luíseduardense para estimular novos trabalhos na mesma área de conhecimento. Reuniram-se trabalhos de pesquisa da área da geografia que abordaram a formação do oeste baiano, afunilando para o município específico, procurando captar as informações que envolvessem principalmente a economia e a segregação, pois fornecem uma base sólida para o entendimento da formação da urbe. Desta forma observou-se que os problemas urbanos estão arraigados na formação social. Concluindo, então, que os processos migratórios e a disparidade econômica influenciam diretamente na segregação físico-territorial atual.

Palavras-chave: Espaço intraurbano, Oeste da Bahia, Luís Eduardo Magalhães, Urbanismo, Segregação.

\section{LUÍS EDUARDO MAGALHÃES/BA'S URBAN DEVELOPMENT: ECONOMY AND SEGREGATION}

\section{ABSTRACT}

Luís Eduardo Magalhães is a city from the mesoregion of extreme west of Bahia state. With less than two decades of emancipation and so many problems associated with its urban configuration, there are not studies which were publicated addressing this localization under an analysis from the architect and urbanist's review. With this work, we are able to aim the introduction about the science knowlogde of Luís Eduardo Magalhães' intra-urban space, in order to stimulate new works in the same knowlodge area. Research works about geography area which address the formation of the west of Bahia were reunited. Then, it was specified to the referenced town, at the same time we figure out to get the information which embrace above all the economy and segregation, because they give us a solidified basis to the understanding of the city formation. This way we noticed that the urban problems are entrenched in the social formation. So we can conclude like this that the migratory processes and the economic inequality influence directly to the present physical and territorial segregation.

Keywords: Intra-URban space; West of Bahia; Luís Eduardo Magalhães; Urbanism; Segregation.

\section{INTRODUÇÃO}

O presente artigo relata a situação atual de que se encontra a cidade e a população urbana de Luís Eduardo Magalhães, uma recente aglomeração urbana do oeste do estado da Bahia. O entendimento do território urbano de qualquer cidade brasileira é importante para construir o conhecimento teórico acerca do tema. Só assim será possível propor reformas que realmente atinjam as raízes dos problemas humanos relacionados ao sítio físico que habitam. 
Existem poucos estudos urbanos sobre o oeste do estado, especialmente sobre a cidade tratada, que relate seu espaço urbano dentro da área de estudo do arquiteto e urbanista. Por ter um crescimento acelerado, e já apontar problemas graves como a segregação físico-territorial, étnico-cultural e socioeconômica, é imprescindível a abertura de um olhar científico sob ela.

Cidades cuja história é mais longa, e os problemas são traumáticos e enraizados não dão a falsa impressão que estão temporariamente enfermas como nas jovens. O costume de viver com estes problemas no Brasil faz parecer que estes fatores estão dentro da normalidade, mas não estão. Teóricos, como o geógrafo Flávio Villaça, por exemplo, conseguem enxergar estes problemas e apontá-los em seus estudos e publicações, dando base para ações de controle que possam vir a surgir da iniciativa pública e privada. Por isso muitos estudos relacionam a dinâmica territorial, econômica, política e histórica de cidades, como as que foram selecionadas para este trabalho.

O objetivo é apontar as fragilidades e potencialidades que compuseram os recentes problemas de Luís Eduardo Magalhães, de como elas surgiram e como se comportam atualmente, de forma que fiquem claros os caminhos a serem tomados para contornar a situação. São a economia e a segregação dois grandes destaques dessa sociedade, sendo paralelos a um único contexto.

\section{METODOLOGIA}

O método para a realização da pesquisa é qualitativo, recorrendo à bibliografia existente no campo dos assuntos urbanos e geográficos sobre o oeste da Bahia e Luís Eduardo Magalhães. Buscaram-se dados acerca da história, economia, sociedade, cultura e espaço urbano da região, porém mais especificamente ao da cidade tratada. Recolheram-se informações que comprovassem os fatos perceptíveis ao olhar do arquiteto e urbanista sob um espaço urbano. $\mathrm{E}$ para melhor organizar o trabalho, ele fora divido em duas partes: oeste baiano, retratando a região, e Luís Eduardo Magalhães (LEM), sobre o município em questão.

\section{OESTE BAIANO}

De acordo com Brandão (2010), a primeira fase do território do atual oeste do estado da Bahia, que ele coloca de 1501 a 1827 (período em que pertencia à Província de Pernambuco), não influencia diretamente na história atual da região, já que aquele desempenho territorial fora ritmado apenas por cotidianidades. $\mathrm{O}$ ano de 1827, com a então posse da Província da Bahia, o progresso paulatinamente, começa a surgir através da constituição do Meio Natural, que se instaura quando a natureza é a maior provedora das "[...] divisões social e territorial do trabalho [...]" (SANTOS, 2002 apud BRANDÃO, 2010, p. 38), e é dado início a segunda fase da história do oeste.

Em meados do século XIX algumas empresas se situaram nas regiões interioranas da Bahia para modernizar a produção agrícola ainda imatura, mas não obtiveram resultados satisfatórios devido à falta de solicitação para exportação, além da dificultosa condição de acessibilidade aos centros exportadores brasileiros (BRANDÃO, 2010). A Bacia fluvial do Rio São Francisco começava a preocupar as autoridades baianas por não se desenvolver, e então criaram a companhia de navegação a vapor do Rio São Francisco, em vista de estimular o comércio e urbanização no "Além São Francisco" (BRANDÃO, 2010, p. 36). Posteriormente, com a ampliação de uma ferrovia que ligaria Juazeiro, a beira do rio, com a capital do estado, Salvador, chamada Ferrovia Centro Atlântica, finalmente houve possibilidade de uma conexão do oeste ao desenvolvimento (BRANDÃO, 2010).

O início do século XX representou para o oeste baiano o inchaço da população local, visto que migravam de outras regiões do estado trabalhadores interessados na crescente economia, 
que era baseada na borracha de mangabeira (DINIZ, 1982 apud BRANDÃO, 2010). Na segunda metade deste século, com a política neoliberal no Brasil, o capital estrangeiro teve facilidade em se inserir no setor econômico da pecuária e da agricultura (LIMA, 2015). Inclusive, a abertura do centro do Brasil com a criação de Brasília, e a rodovia BR-020, que a liga ao nordeste, consolidouse o oeste na rede nacional (BRANDÃO, 2010). Novamente a população aumentava, mas agora recebendo migrantes de outros estados brasileiros e até do exterior (LIMA, 2015).

Os migrantes do sul do Brasil (dos estados do Paraná, Santa Catarina e Rio Grande do Sul), genericamente ficaram conhecidos ali como gaúchos, e possuem a maior representatividade dos forasteiros locais, com participação efetiva da economia até a cultura instaurada ali (ALVES, 2006; MONDARDO, 2013). A nova dinâmica financeira e territorial não só auxiliou os núcleos urbanos já existentes a se desenvolverem, como também criou novos ecúmenos, fortalecendo a rede urbana regional (BRANDÃO, 2010).

A cidade de Barreiras já havia nascido do período colonial do Brasil, mas não tinha expressão nenhuma. Depois deste desenvolvimento no oeste, e as rodovias BR-020 e BR-242, ambas cruzando o território municipal, houve o surgimento de muitas indústrias agrícolas e migrantes interestaduais (ALVES, 2006). Os grandes proprietários rurais acabaram desestimulando a concorrência dos pequenos, encaminhando os segundos a um êxodo rural, e consequentemente enxertando a população urbana junto aos sulistas. Porém, muitos forasteiros passaram a morar em suas propriedades rurais, e começaram a surgir os povoados, como é o caso do Mimoso do Oeste, dentro do território barreirense, e futuro Luís Eduardo Magalhães (LEM) (ALVES, 2006).

\section{LUÍS EDUARDO MAGALHÃES (LEM)}

A atual área da cidade, quando ainda pertencia ao município de Barreiras, até por volta do ano de 1980, havia apenas um boteco oferecendo serviço aos passantes das BR-242 e BR-020 no entroncamento entre ambas (SCHLOSSER, 2014). Então um posto de combustível (Posto Mimoso) instalado pelo empresário goiano Arnaldo Horácio Ferreira contribuiu para o desenvolvimento de uma vila que abrigava novos migrantes sulistas a cada ano, que vinham interessados no preço das terras, e apostando na nova política agrícola do país (ALVES, 2006).

$\mathrm{O}$ intenso fluxo de veículos das rodovias favoreceu para que aquele ponto emergisse, e em 1984 a CARIG (Colonizadora e Administradora Vale do Rio Grande) criou o loteamento Rancho Grande, que fora primeiramente habitado por produtores rurais da região sul do Brasil (SCHLOSSER, 2014). Este loteamento posteriormente passou a se chamar Mimoso do Oeste como uma homenagem ao posto que deu início ao núcleo urbano (RIOS FILHO, 2012). Apenas em 1986 o povoado se oficializou de Barreiras (FONSECA, SILVA e VIEIRA, 2010 apud BRANDÃO, 2013). A partir de então muitos outros empreendedores obtiveram lucro com a criação e venda de mais terras urbanas, e comércio e serviços suplementares surgiam para atender ao povoado que emergia cada vez mais aceleradamente (ALVES, 2006).

Membros da AMMO (Associação dos Moradores do Mimoso do Oeste) foram responsáveis por dar início ao processo que, em 8 de outubro de 1997, tornou o Mimoso do Oeste distrito de Barreiras pela Lei № 034 (SCHLOSSER, 2014). E, devido ao distrito ser povoado por grande parte de forasteiros, estes almejavam a autonomia política e administrativa do lugar, que, estrategicamente localizado entre fácil contato com a Brasília, Salvador e Palmas (figura 1), tinha potencial para escoamento da produção (ALVES, 2006). Esta gana e a resistência de Barreiras por ceder território escancarou a rivalidade étnico-cultural entre os povos locais (ALVES, 2006). Observações de Haesbaert (1997 apud ALVES, 2006) acerca desse conflito, entre principalmente sulistas e nordestinos, apontaram para o domínio do território como afirmação identitária de um determinado grupo, no caso, dos migrantes em segregação aos nativos. Então, findando esta 
peleja, em março de 2000 houve a emancipação do distrito, trazendo 4.018,778 km² de terras para o município de Luís Eduardo Magalhães (LEM, 2016).

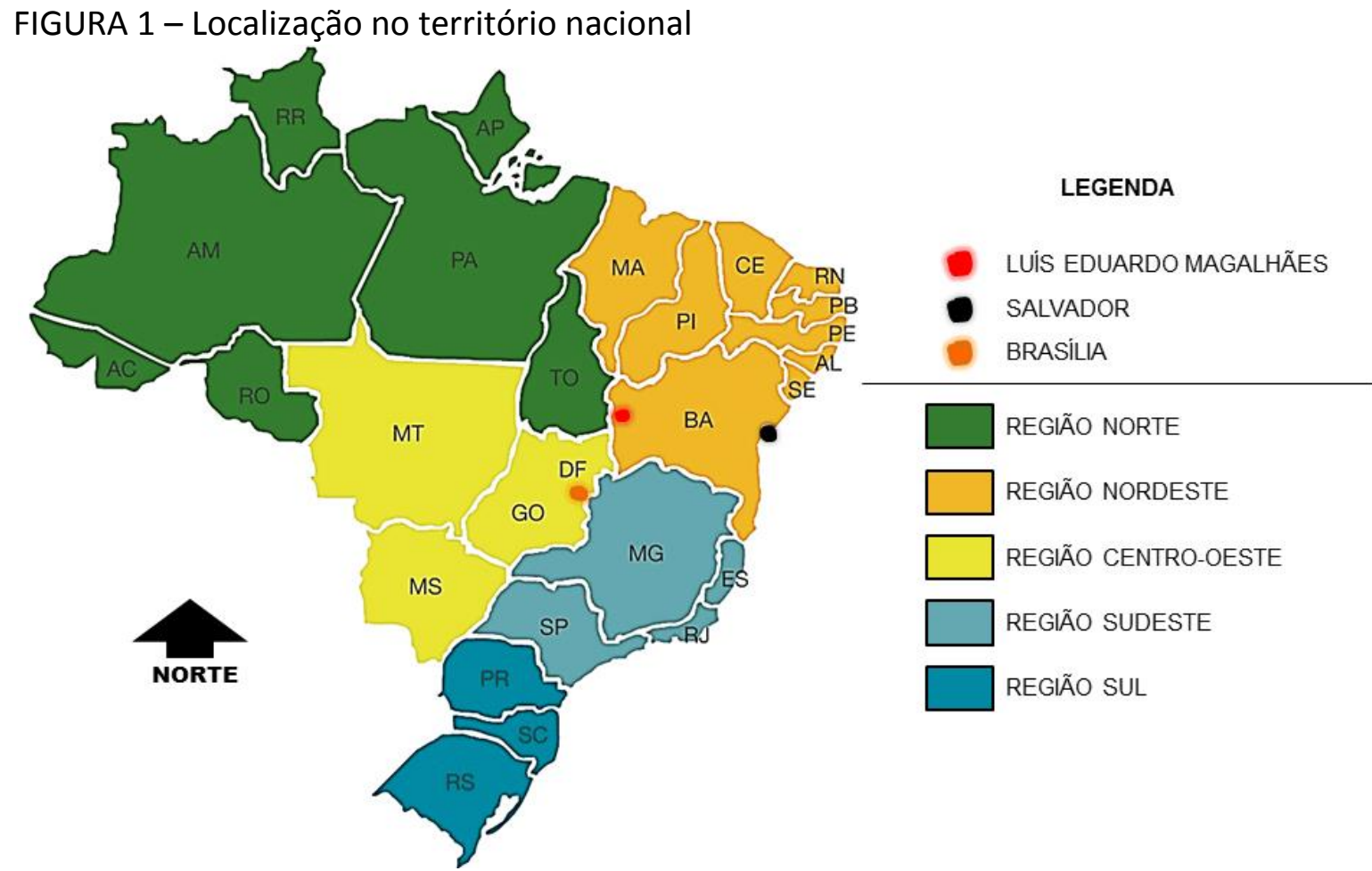

Fonte: Pro Noticia (2016). Editada pela autora (2017).

De acordo com Alves (2006, p. 97), o município detém-se como o "[...] principal centro econômico dos cerrados nordestinos [...]", com variadas empresas do setor agrícola com sedes em seu território. Sua base econômica é a agricultura, e, segundo Lima (2015), é a produção agrícola que mantém a economia, principalmente pelos grãos: soja, milho e algodão. Schlosser (2014) salienta o aporte tecnológico e científico valorizando a produção e o produto. A Feira Internacional de Tecnologia Agrícola, a Bahia Farm Show, acontece apenas na cidade (dentre o nordeste), evidencia a movimentação econômica em nome deste setor (ALVES, 2006).

O conceito do localismo se aplica bem ao município, já que aplicam-se parcerias e estratégias empresariais que visibilizam e viabilizam benefícios de mais investimentos, e a feira agrícola é uma forma de amostra do potencial regional para nível nacional e internacional (FONSECA, 2013 apud LIMA, 2015). Resultado destes intentos está o crescente número de serviços voltados para a agricultura, desde consultorias até maquinários (BRANDÃO, 2010).

Paralelamente ao desenvolvimento econômico satisfatório para os agricultores, surgem os problemas sociais para os indiretamente envolvidos nesta parte da história de LEM. O crescimento acelerado da cidade e os altos índices econômicos são correlacionados aos sulistas pela população, como forma de justificar a prosperidade, e é um fator que aumenta a disparidade e o preconceito para com os nativos (ALVES, 2006). Além do mais, muitos migrantes vieram após certa estabilidade da economia em busca de empregos industriais e/ou urbanos (e não mais rurais, já que a alta tecnologia dispensa a mão de obra humana), e muitos deles não têm capacitação técnica e especializada pra se adequar aos padrões exigidos para as oportunidades, então muitos tem que sobreviver da marginalidade e informalidade (ALVES, 2006; SANTOS, 2007). 
De acordo com Mondardo (2013) a desigualdade na distribuição de renda se reverbera no espaço urbano quando o categoriza por áreas nobres e pobres. São exemplos representativos para esta teoria, respectivamente, os bairros Jardim Paraíso e Santa Cruz. Os primeiros migrantes foram os que tiveram mais chances de ascenderem economicamente, e muitos deles tornaram-se grandes proprietários rurais, e alguns também aprenderam a fazer negócio com o mercado imobiliário, tornando-se grandes agentes modificadores da terra urbana (ALVES, 2006). Relacionadamente e justificado pelo processo evolutivo de LEM, os sítios mais valorizados estão ocupados predominantemente pela parcela branca e sulista, e os menos pela população negra e nordestina (ALVES, 2006). A arquitetura e as manifestações culturais são mais exemplos da hegemonia forasteira dos gaúchos sobre este território, cada vez mais reafirmando seu poderio sob o lugar (SANTOS, 2007).

Indícios negativos da atualidade, como a dependência da tecnologia e de quem a dá (SANTOS; CHAMMA, 2009), e das cidades desse período como a sobrevalorização dos espaços privados em detrimento dos públicos (MENDONÇA, 2007), são detectados em LEM (RIOS FILHO, 2012). Alves (2006) acusa estes sintomas pela incapacidade dos espaços públicos em exercerem sua função. Este autor exemplifica esta teoria através das características das ruas, cujas calçadas não estimulam o contato entre os habitantes, e, pelas esparsas localizações (geradas pela especulação imobiliária), praticamente são usadas apenas por veículos automotores, na maioria, particulares. Outros modos de segregação comprovados na cidade são os condomínios horizontais para as classes mais altas, onde vivem os agricultores (ALVES, 2006).

Segundo Alves (2006) e Santos (2007), o bairro Santa Cruz ainda cultiva as características da cultura nordestina e mantém suas ruas vívidas, porém, pelos seus índices de qualidade social baixos, detém problemas como a prostituição infantil, disseminação de drogas ilícitas e violência, principalmente em seus pontos mais periféricos. Problema que se repete em outros locais da cidade com as mesmas características. Este bairro também se encaixa no perfil de subcentro descrito por Villaça (2007), pela quantidade de comércio e serviços voltados àquela população. Já bairros como o Jardim Paraíso, que abrigam a população burguesa, não possuem tantos estabelecimentos comerciais porque fazem usufruto dos localizados no centro da cidade, pois tem acessibilidade até lá (RIOS FILHO, 2012). Esses bairros nobres também tem uma vida pública das ruas mais apática e são amostras do poder financeiro de seus habitantes (ALVES, 2006).

Rios Filho (2012, p. 197) define a segregação socioespacial de Luís Eduardo Magalhães é mais violenta do que das metrópoles brasileiras, já que "[...] ao mesmo tempo em que possibilita a elite fazer uso do centro de consumo da cidade, promove o distanciamento físico e social das pessoas de baixa renda".

\section{CONCLUSÃO}

Em suma, Luís Eduardo Magalhães é uma jovem cidade que já passa por problemas urbanos graves, como a segregação e suas consequências como a violência. A desvalorização do núcleo urbano como local de convívio público e espaço da cidadania, está a diminuindo a qualidade de vida dos muitos habitantes. Percebe-se a necessidade de políticas públicas urbanas e sociais que controlem a construção física da urbe, assim como das migrações, oferecendo, acima de tudo, possibilidade de compartilhamento e aproximação entre povos distintos, para enfim consumar-se o direito à qualidade de vida geral, e não específica.

\section{REFERÊNCIAS BIBLIOGRÁFICAS}

ALVES, V. E. L. Mobilização e modernização nos cerrados piauienses: Formação territorial no império do agronegócio. 2006. Tese (Doutorado) - Faculdade de Filosofia, Letras e Ciências Humanas, Universidade de São Paulo, São Paulo - SP. 
BRANDÃO, P. R. B. A formação territorial do Oeste Baiano: a constituição do "Além São Francisco" (1827-1985). GeoTextos, vol. 6, n. 1, p. 35-50, jul. 2010.

LIMA, J. S. A construção da Feira de Tecnologia Agrícola e Negócios no município de Luís Eduardo Magalhães/BA. In: ENCONTRO NACIONAL DA ANPEGE, 11., 2015, Presidente Prudente. Anais... Presidente Prudente: Anpege, 2015. p. 7354-7365.

LUÍS EDUARDO MAGALHÃES (LEM). Prefeitura Municipal. A Cidade. 2016. Disponível em <http://soudelem.com.br/a-cidade/>. Acesso em: fev. 2017.

MENDONÇA, E. M. S. Apropriações do espaço público: alguns conceitos. Estudos e Pesquisas em Psicologia, Rio de Janeiro, v. 7, n. 2, ago., 2007. Disponível em: <http://www.epublicacoes.uerj.br/index.php/revispsi/article/view/10926/8617>. Acesso em: 03 abr. 2017.

MONDARDO, M. L. Territórios Precários: Desequilíbrios entre o crescimento econômico e o desenvolvimento social no Oeste da Bahia. ACTA Geográfica, Boa Vista, v. 7, n. 15, p. 85-101, mai./ago. 2013.

PRO NOTICIA. Mapa do Brasil. 2016. Disponível em: <http://www.pronoticia.com/educacao/geografia/mapa-brasil.html>. Acesso em: 22 fev. 2017.

RIOS FILHO, J. N. V. Segregação socioespacial na cidade do agronegócio de Luís Eduardo Magalhães (BA). 2012. 209 f. Dissertação (Mestrado em Geografia) - Instituto de Geociências, Universidade Federal da Bahia. Salvador - BA.

SANTOS, C. C. M. Oeste da Bahia: Modernização com (des)articulação econômica e social de uma Região. 2007. Tese (Doutorado) - Faculdade de Filosofia e Ciências Humanas, Universidade Federal da Bahia, Salvador - BA.

SANTOS, N. L.; CHAMMA, P. V. C. Globalização e espaço urbano. In: JORNADA DOS CURSOS DE HISTÓRIA, GEOGRAFIA E ARQUITETURA: ESPAÇO, HISTÓRIA E GLOBALIZAÇÃO, 1., 2009, Bauru. Anais... Bauru: Universidade Sagrado Coração, 2009. p. 17-23.

SCHLOSSER, J. B. A. S. Características históricas e da gestão de políticas públicas de cultura do município de Luís Eduardo Magalhães. 2014. 39 f. Monografia (Especialização em Gestão Cultural) - Instituto de Humanidades, Artes e Ciências, Universidade Federal da Bahia, Salvador - BA.

VILLAÇA, F. Espaço intra-urbano no Brasil. 2. ed. São Paulo: Studio Nobel: Fundação de Amparo à Pesquisa do Estado de São Paulo, 2007. 